\title{
Article \\ Structure and Strength of Isothermally Heat-Treated Medium Carbon Ti-V Microalloyed Steel
}

\author{
Stefan Dikić $^{1, *}$, Dragomir Glišić ${ }^{1}$,, Abdunnaser Fadel $^{2}$, Gvozden Jovanović ${ }^{3}$ and Nenad Radović ${ }^{1, *(1)}$ \\ 1 Faculty of Technology and Metallurgy, University of Belgrade, Karnegijeva 4, 11120 Belgrade, Serbia; \\ gile@tmf.bg.ac.rs \\ 2 Department of Petroleum Engineering, Faculty of Natural Resources, Al Zawia University, \\ Al Zawia 16418, Libya; naser.fadel2369@gmail.com \\ 3 Department of Metallurgical and Environmental Engineering, Institute for Technology of Nuclear and Other \\ Mineral Raw Materials, Bulevar Franš d’Eperea 86, 11000 Belgrade, Serbia; g.jovanovic@itnms.ac.rs \\ * $\quad$ Correspondence: sdikic@tmf.bg.ac.rs (S.D.); nenrad@tmf.bg.ac.rs (N.R.); Tel.: +381-11-330-3759 (S.D.)
}

Citation: Dikić, S.; Glišić, D.; Fadel,

A.; Jovanović, G.; Radović, N.

Structure and Strength of

Isothermally Heat-Treated Medium Carbon Ti-V Microalloyed Steel.

Metals 2021, 11, 1011. https://

doi.org/10.3390/met11071011

Academic Editor: Alberto

E. Monsalve

Received: 20 May 2021

Accepted: 19 June 2021

Published: 24 June 2021

Publisher's Note: MDPI stays neutral with regard to jurisdictional claims in published maps and institutional affiliations.

Copyright: (c) 2021 by the authors. Licensee MDPI, Basel, Switzerland. This article is an open access article distributed under the terms and conditions of the Creative Commons Attribution (CC BY) license (https:// creativecommons.org/licenses/by/ $4.0 /)$.

\begin{abstract}
Isothermal transformation characteristics of a medium carbon $\mathrm{Ti}-\mathrm{V}$ microalloyed steel were investigated using light microscopy, scanning electron microscopy (SEM) equipped with energy dispersive spectroscopy (EDS), and by uniaxial compressive testing. Samples austenitized on $1100{ }^{\circ} \mathrm{C}$ were isothermally treated in the range from 350 to $600^{\circ} \mathrm{C}$ and subsequently water quenched. The final microstructure of the samples held at $350{ }^{\circ} \mathrm{C}$ consisted of bainitic sheaves and had compressive yield strength, approximately from $1000 \mathrm{MPa}$, which is attributed to high dislocation density of low bainite. At 400 and $450{ }^{\circ} \mathrm{C}$, acicular ferrite became prevalent in the microstructure. It was also formed by a displacive mechanism, but the dislocation density was lower, leading to a decrease of compressive yield strength to approximately $700 \mathrm{MPa}$. The microstructure after the heat treatment at $500{ }^{\circ} \mathrm{C}$ consisted of coarse non-polygonal ferrite grains separated by pearlite colonies, principally dislocation free grains, so that the compressive YS reached a minimum value of about $700 \mathrm{MPa}$. The microstructure of the samples heat-treated at 550 and $600{ }^{\circ} \mathrm{C}$ consisted of pearlite and both grain boundary and intragranular ferrite, alongside with some martensite. After $600 \mathrm{~s}$, austenite became stable and transformed to martensite after water quenching. Therefore, the presence of martensite increased the compressive YS to approx. $800 \mathrm{MPa}$.
\end{abstract}

Keywords: medium carbon microalloyed steels; bainite; acicular ferrite; incomplete reaction phenomenon; multiphasic steel; retained austenite

\section{Introduction}

Demands for materials that provide good mechanical properties, along with weight reduction and cheap manufacturing process, are constantly increasing. Medium carbon microalloyed steels are intended to attain similar strength/toughness levels to that of quenched and tempered steel by air cooling from the temperatures of hot working. In this manner, the process of quenching and tempering would be avoided, which would consequently shorten the production time and considerably lower the expenses [1]. The final microstructure and mechanical properties of medium carbon microalloyed steels depend on their chemical composition and thermomechanical treatment, which refers to controlled continuous cooling after hot working. The main role of microalloying elements-titanium (Ti), vanadium $(\mathrm{V})$, and niobium $(\mathrm{Nb})$ - is to control grain size at high temperatures and to increase yield strength through mechanisms of grain refinement by austenite grain boundary pinning and retardation of recrystallization, as well as through the mechanism of dispersion strengthening of ferrite. Vanadium nitrides and carbo-nitrides have a relatively high solubility product, compared to $\mathrm{Ti}$ and $\mathrm{Nb}$ nitrides and carbides; therefore, they are able to precipitate at lower temperatures in ferrite where they can impose the strongest strengthening effect $[2,3]$. The influence of carbides and nitrides of microalloying elements 
is rather circumstantial; by providing the suitable sites for heterogeneous nucleation of the products of austenite decomposition [4].

Depending on the alloying content and the cooling rate, the microstructure of continuously cooled medium carbon microalloyed steel from the temperature of hot working could be in general ferritic-pearlitic or bainitic, but it may contain acicular ferrite, Widmanstätten ferrite, different morphologies of grain boundary and intragranular ferrites, and retained austenite and martensite [5]. Acicular ferrite forms by the same reaction as bainite, except that the nucleation site shifts from the grain boundaries to the grain interiors at the second phase particles [6-8].

Although satisfactory strength levels alongside the fatigue resistance have been attained, the toughness of the ferritic-pearlitic medium carbon microalloyed steels is still considerably lower compared with that of quenched and tempered steels [1]. Results of previous research indicate that the fine interlocked structure of acicular ferrite has a beneficial effect on the toughness of the medium carbon microalloyed steels [9-11]. Vanadium-nitride particles, in addition to their role in precipitation hardening, are found to be highly effective as a preferential place for intragranular nucleation of acicular ferrite [12-15]. In this way, the addition of vanadium together with high nitrogen levels in the steel favors the formation of acicular ferrite at the expense of bainite [15] and thus acts in the direction of fracture toughness improvement. However, there are questions about the strength of the steels with bainitic or acicular ferrite structure, which seems to be relatively low compared with the medium carbon microalloyed steels with ferrite-pearlite structure [7].

There is therefore interest in evaluating the contribution of individual microstructural components to the overall strength of the medium carbon microalloyed steels, in order to find a way to improve their mechanical properties and to further expand their application.

To estimate the contribution of the individual microconstituents to the overall strength of the steel, investigation of austenite decomposition of the steel in isothermal conditions seems to be a convenient method. A range of microconstituents attained at different temperatures of isothermal holding in this work was used with the aim of evaluating their impact on the strength of a medium carbon Ti-V microalloyed forging steel with a high level of nitrogen content.

\section{Material and Methods}

The chemical composition of medium carbon Ti-V microalloyed steel tested in this research is given in Table 1. The steel was produced by full-scale casting followed by hot forging and hot rolling into $19 \mathrm{~mm}$ and $22 \mathrm{~mm}$ diameter bars. In order to control the shape of sulfide inclusions, a small amount of $\mathrm{Ca}$ (approximately $40 \mathrm{ppm}$ ) was added. Bar samples were homogenized in a laboratory furnace at $1250^{\circ} \mathrm{C}$ for $4 \mathrm{~h}$ in argon as a protective atmosphere and quenched in oil. Specimens, $12 \mathrm{~mm}$ high discs, cut from homogenized bars, were austenitized at $1100{ }^{\circ} \mathrm{C}$ for $600 \mathrm{~s}$ in argon atmosphere and subsequently transferred directly into a salt bath for further isothermal treatment at temperatures in the range from $350{ }^{\circ} \mathrm{C}$ to $600{ }^{\circ} \mathrm{C}$, for different holding times varying from $2 \mathrm{~s}$ to $1200 \mathrm{~s}$, followed by water quenching.

Table 1. Chemical composition of experimental steel (wt $\%)$.

\begin{tabular}{cccccccccccccc}
\hline $\mathbf{C}$ & $\mathbf{S i}$ & $\mathbf{M n}$ & $\mathbf{P}$ & $\mathbf{S}$ & $\mathbf{C r}$ & $\mathbf{N i}$ & $\mathbf{C u}$ & $\mathbf{A l}$ & $\mathbf{M o}$ & $\mathbf{T i}$ & $\mathbf{V}$ & $\mathbf{N b}$ & $\mathbf{N}$ \\
\hline 0.309 & 0.485 & 1.531 & 0.0077 & 0.0101 & 0.265 & 0.20 & 0.232 & 0.017 & 0.041 & 0.011 & 0.123 & 0.003 & 0.0221 \\
\hline
\end{tabular}

Metallographic specimens from isothermally treated samples were prepared mechanically by grinding, polishing with $1 \mu \mathrm{m}$ diamond paste, and etching in a $2 \%$ nital. Microstructures were examined using light microscopy Reichart-Jung MeF3 (Viena, Austria) and scanning electron microscopy JEOL JSM 5800 (Tokyo, Japan) equipped with EDS (Oxford Instruments Inca, United Kingdom). Detailed analysis of microstructural development after different isothermal decomposition times provided information for developing a time-temperature-transformation (TTT) diagram. 
Yield strength, $\mathrm{Rp}_{0.2}$, was evaluated using compression testing at room temperature, performed by a servo-hydraulic testing machine Instron Model 1332 (Norwood, MA, USA), using $5 \mathrm{~mm}$ long cylindrical specimens $5 \mathrm{~mm}$ in diameter, at speed of $0.5 \mathrm{~mm} \mathrm{~min}{ }^{-1}$, which corresponds to an initial strain rate of approximately $4 \times 10^{-4} \mathrm{~s}^{-1}$, from offset yield strengths at plastic strains of $0.2 \%$. In order to assess higher accuracy, thermomechanically processed samples were cut into two pieces, one for metallographic examination and the other for compression testing, as suggested in [16].

Prior austenite grain boundaries were revealed by using a combination of heat treatment and thermal etching [17]. Prior austenite grain size was measured by the linear intercept method.

\section{Results and Discussion}

\subsection{Microstructure}

The TTT diagram shown in Figure 1 exhibits a typical C-curve in the bainitic region, with the "nose" approximately at $450^{\circ} \mathrm{C}$. Calculation of the bainite start temperature $\left(B_{\mathrm{S}}\right)$ using an empirical equation [18] gives the value of $534{ }^{\circ} \mathrm{C}$, which agrees well with the position of the curve in the TTT diagram. Below that temperature austenite transforms by bainitic mechanism, forming either bainite or acicular ferrite (indicated in the diagram as $\mathrm{BS}(\mathrm{AF})$ ). Above $B_{\mathrm{S}}$ temperature, austenite decomposition takes place by a diffusional mechanism, and the onset of grain boundary ferrite (GBF), intragranular ferrite (IGF), and pearlite $(\mathrm{P})$ in the microstructure are indicated in the diagram in Figure 1. The reaction finish $\left(R_{f}\right)$ was assumed to be the transformation time when no visible changes in the microstructure could be further detected.

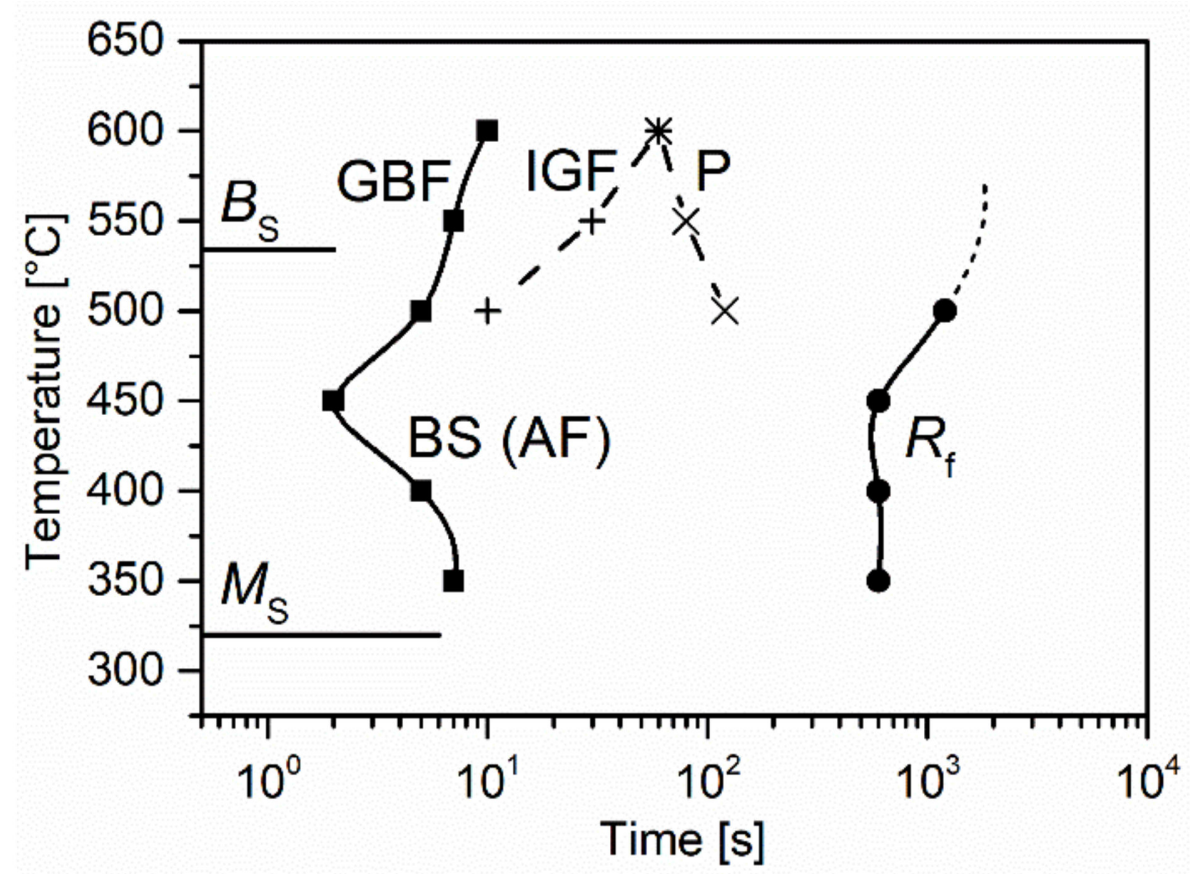

Figure 1. Experimental TTT diagram with corresponding microconstituents indicated: BS, bainite sheaves; AF, acicular ferrite; GBF, grain boundary ferrite; IGF, intragranular ferrite; and P, pearlite.

The microstructure of the samples isothermally treated at $350{ }^{\circ} \mathrm{C}$, Figure $2 \mathrm{a}$, consists mainly of bainitic sheaves (BS) — parallel bainitic ferrite plates emanating from the prior austenite grain boundaries but smaller sheaves of intragranularly nucleated ferrite plates can also be observed. 


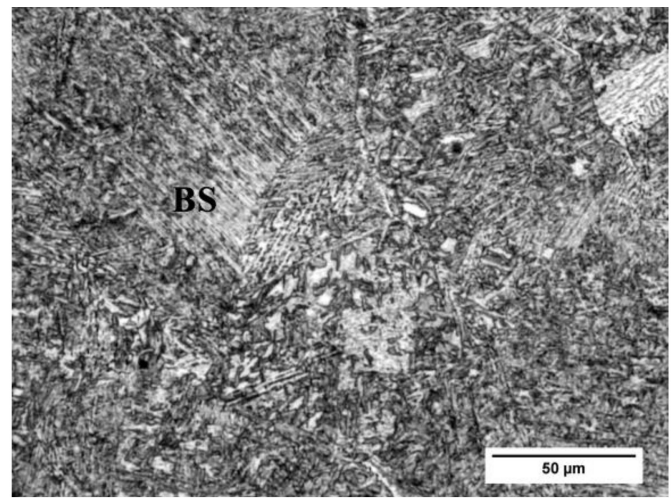

(a)

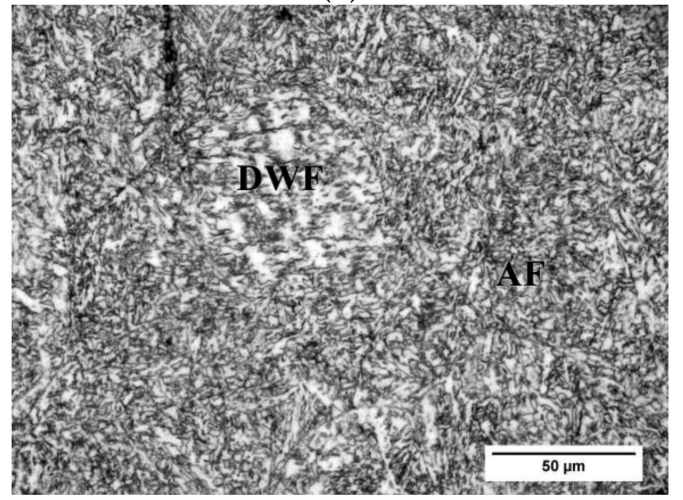

(c)

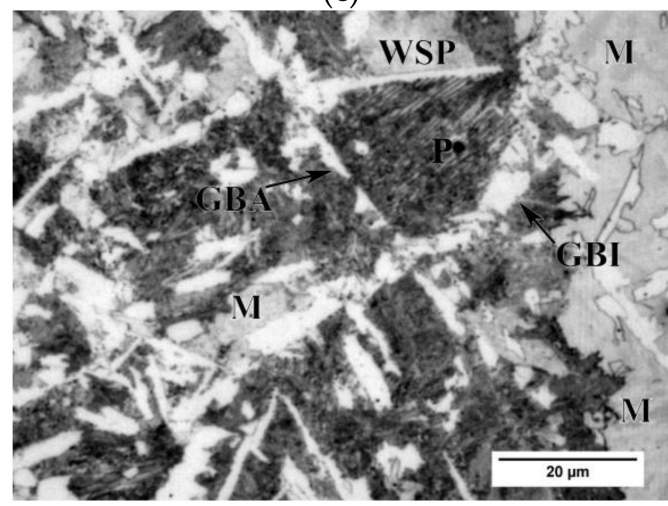

(e)

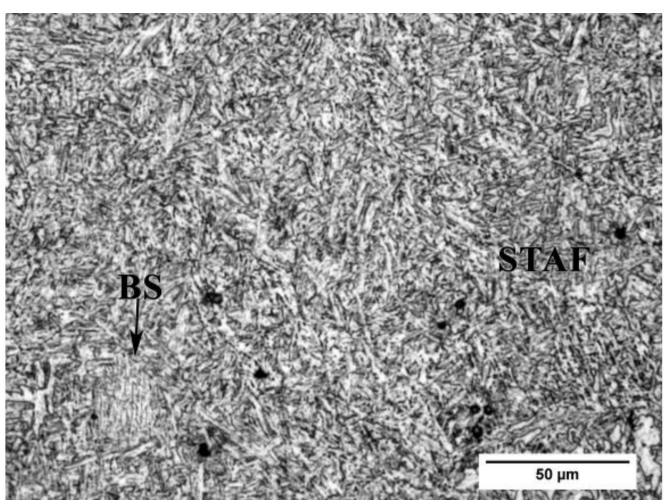

(b)

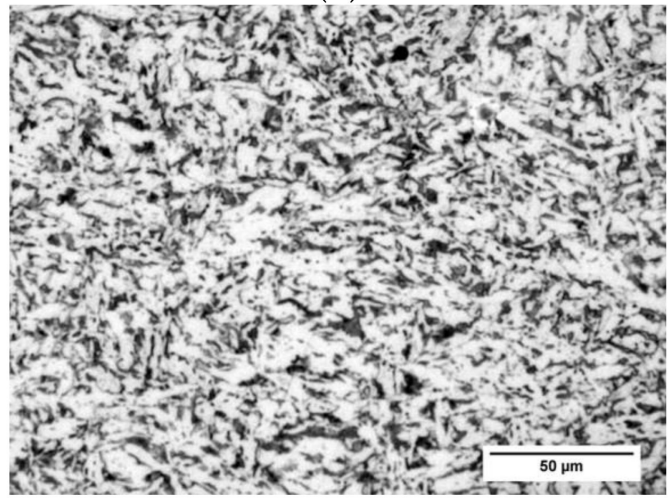

(d)

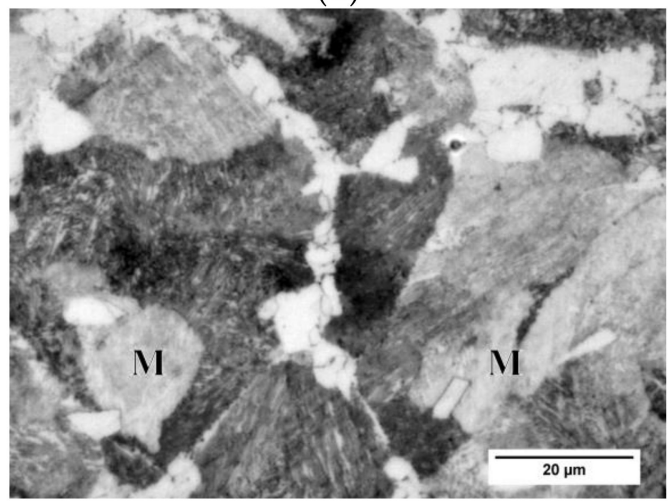

(f)

Figure 2. Microstructures of Ti-V steel after $1200 \mathrm{~s}$ of isothermal transformation at: (a) $350{ }^{\circ} \mathrm{C},(\mathbf{b}) 400{ }^{\circ} \mathrm{C},(\mathbf{c}) 450{ }^{\circ} \mathrm{C},(\mathbf{d}) 500{ }^{\circ} \mathrm{C}$, (e) $550{ }^{\circ} \mathrm{C},(\mathbf{f}) 600^{\circ} \mathrm{C}$.

Increasing the temperature of isothermal transformation to $400{ }^{\circ} \mathrm{C}$, intragranular nucleation becomes prevalent, and microstructure after $1200 \mathrm{~s}$ consists mostly of interlocked sheaves of ferrite plates, along with some individual interlocked ferrite plates, denoted in Figure $2 b$ as sheaf type acicular ferrite (STAF) and interlocked type acicular ferrite (AF). It is a generally accepted stance that acicular ferrite represents an intragranularly nucleated bainite $[8,11]$. Furthermore, the two observed intragranularly formed morphologies, interlocked sheaves of ferrite plates, and individual interlocked ferrite plates also indicate lower and upper acicular ferrite, analogous with lower and upper bainite $[10,19]$. In order to examine the development of the structure in the early stages of the transformation at $400{ }^{\circ} \mathrm{C}$, the sample was quenched after $20 \mathrm{~s}$. Obtained microstructure, shown in Figure 3, reveals sheaves of ferrite plates formed by sympathetic nucleation that grow into the austenite at a high angle until impingement with another ferrite plate or a sheaf. Simultaneously, sheaves of bainite ferrite plates that grow directly from the austenite grain boundary were found, as in the lower right of the micrograph in Figure 3. 


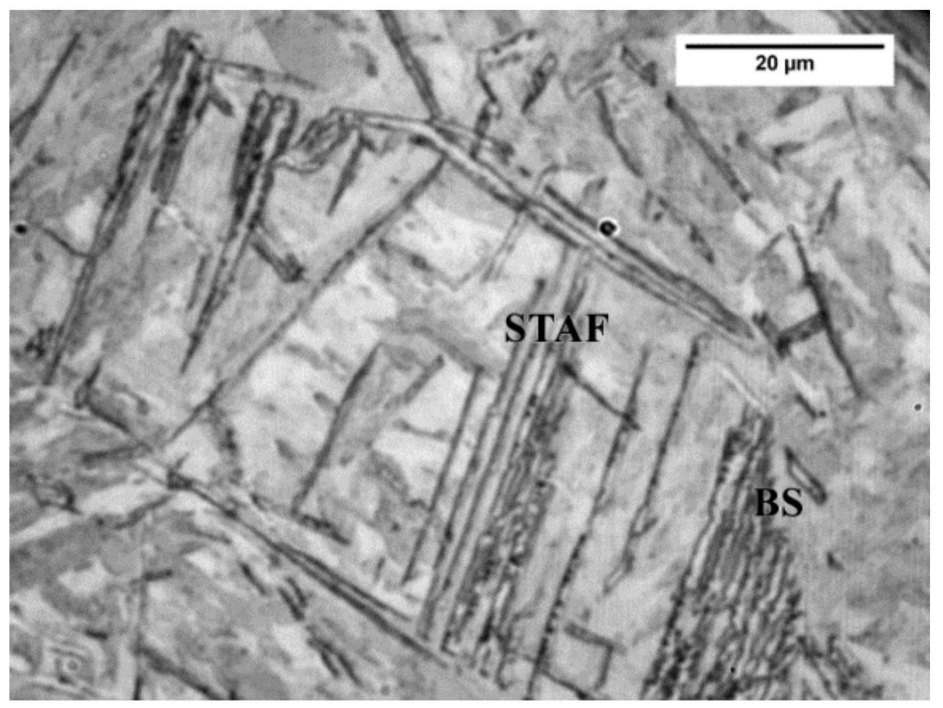

Figure 3. Micrograph of the sample held at $400{ }^{\circ} \mathrm{C}$ for $20 \mathrm{~s}$. Light microscopy.

With rising the temperature of isothermal transformation to $450{ }^{\circ} \mathrm{C}$, grain boundary nucleation is suppressed to a great extent, and the microstructure after $1200 \mathrm{~s}$ prevalently consists of the fine interlocked ferrite plates-interlocking type acicular ferrite, while bainitic sheaves seem absent, as can be seen from the micrograph in Figure 2c. There is also a particular occurrence of a coarse irregular ferrite morphology in the microstructure (Figure 2c), considered as degenerate Widmanstätten ferrite, characteristic of alloyed steels, as a consequence of the solute drag-like effect, primarily by addition of $\mathrm{Cr}$ and $\mathrm{V}$ at the temperatures of isothermal transformation just below the "bay", as seen in the TTT diagram [20]. Formation of such morphology was associated with the mechanism of sympathetic nucleation of rod-like or lath-like ferrite subunits [20-22].

Microstructure in the early stages of the austenite transformation obtained by quenching after 20 s, shown in Figure 4, reveals individual ferrite plates growing into the untransformed austenite at high angles from the primary ferrite plates. It could be concluded that the development of the structure at $450{ }^{\circ} \mathrm{C}$ is dominated by the edge-to-face type of sympathetic nucleation, rendering the observed structure of interlocked type of acicular ferrite.

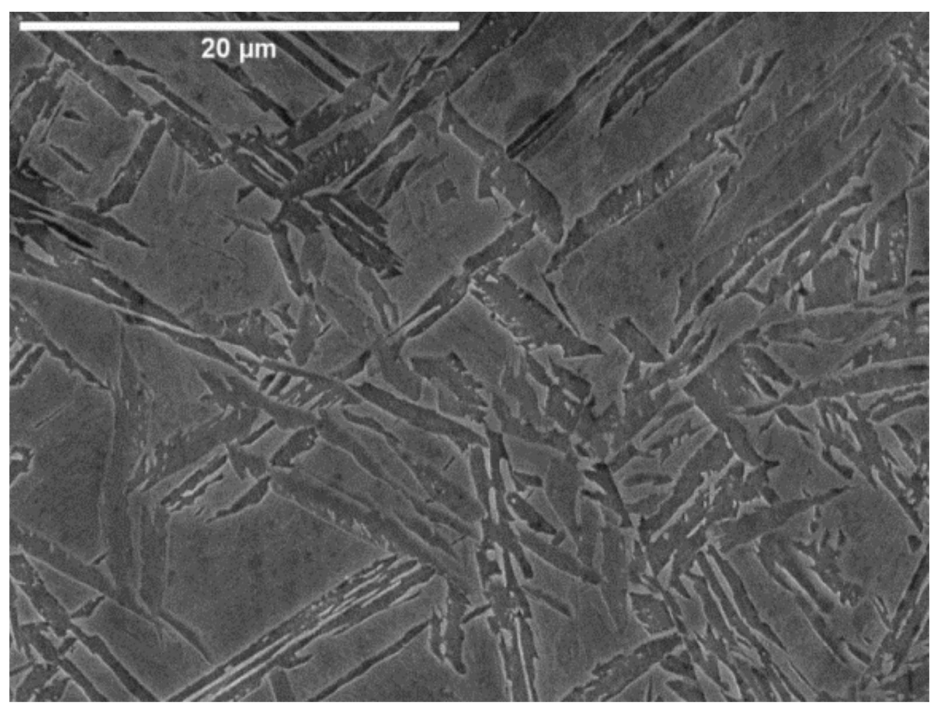

Figure 4. Micrograph of the sample held at $450{ }^{\circ} \mathrm{C}$ for $20 \mathrm{~s}$. SEM.

The microstructure of the sample held at $500{ }^{\circ} \mathrm{C} / 1200 \mathrm{~s}$, presented in Figure $2 \mathrm{~d}$, consists of non-polygonal, coarse, and somewhat elongated ferrite grains, separated by 
the pearlite nodules. However, the microstructure of the samples quenched after $80 \mathrm{~s}$ at $500{ }^{\circ} \mathrm{C}$, shown in Figure 5, reveals that transformation begins by nucleation of coarse Widmanstätten ferrite plates both at austenite grain boundaries and intragranularly at inclusions. An isolated case of ferrite plates growing from the grain boundary allotriomorph as Widmanstätten side plates can also be observed in the lower left side of the micrograph in Figure 5. On the top right, there is a set of parallel but separated, irregular ferrite plates growing directly from the austenite grain boundary, and in the center, there is an example of intragranularly nucleated ferrite plates. Since the transformation temperature of $500{ }^{\circ} \mathrm{C}$ is just below the calculated value of $B_{S}$ temperature of $534{ }^{\circ} \mathrm{C}$ [18], it could be concluded that the transformation begins by displacive mechanism, in a similar manner as at $400{ }^{\circ} \mathrm{C}$ and $450{ }^{\circ} \mathrm{C}$. However, at the upper end of the displacive transformation region, at low undercooling with respect to $B_{\mathrm{S}}$ temperature, austenite decomposition takes place with the low driving force giving rise to the formation of coarse ferrite morphologies such as Widmanstätten ferrite [23]. At the same time, a low carbon concentration profile due to the high diffusivity of carbon atoms at $500{ }^{\circ} \mathrm{C}$ favors sympathetic nucleation of the ferrite subunits at the sides of the plate, while the growth progresses more readily edgewise due to coherency with the neighboring austenite. Additionally, a more uniform distribution of the carbon within untransformed austenite would facilitate sympathetic nucleation and growth of the ferrite sub-units by preventing the formation of the high carbon concentration gradient at the $\gamma / \alpha$ interface that eventually brings to a halt the further process of nucleation and growth of the ferrite [23]. For longer holding times, lath-like or plate-like ferrite morphology cannot be distinguished due to considerable coarsening (Figure 2d). Observed coarsening of ferrite may occur by coalescence and by subsequent diffusional growth [11,24]. Carbon atoms escaping from the growing ferrite at $500{ }^{\circ} \mathrm{C}$ diffuse at longer distances and distribute more evenly within austenite. The enrichment of the untransformed austenite on carbon decreases the $B_{\mathrm{S}}$ temperature and eventually leads to the transformation of the austenite to pearlite.

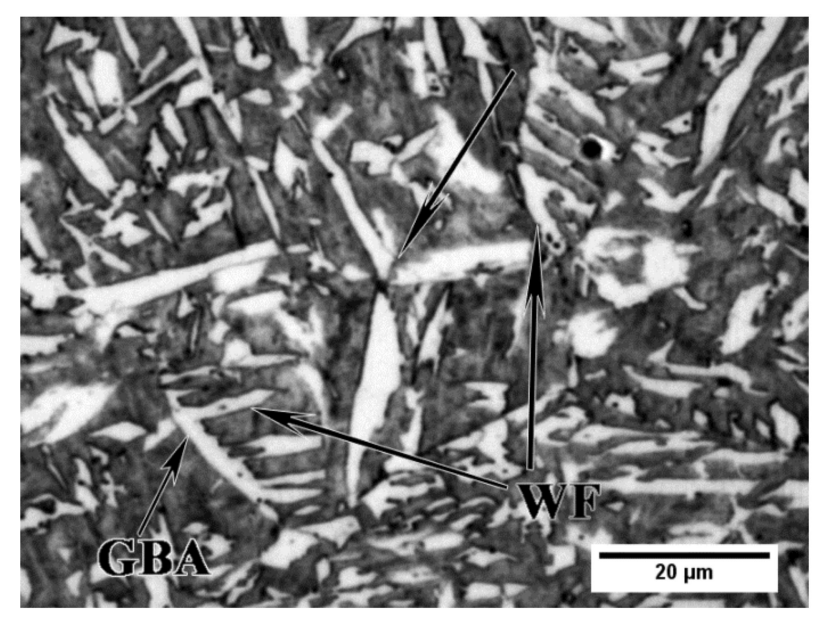

Figure 5. Micrograph of the sample held at $500{ }^{\circ} \mathrm{C}$ for $80 \mathrm{~s}$. Light microscopy.

The results of the microstructural analysis suggest a growing contribution of the intragranular nucleation as the temperature of isothermal transformation is increased from $350{ }^{\circ} \mathrm{C}$ up to the C-curve "nose" on the TTT diagram at $450{ }^{\circ} \mathrm{C}$, and correspondingly, a nucleation event shifts from the austenite grain boundaries to the second phase particles in the grain interiors. Figure 6a shows an SEM micrograph and EDS of the complex MnS inclusion with TiN, along with traces of $\mathrm{Ca}$ that was added in molten steel for the purpose of MnS inclusions shape modification, detected as the site of intragranular nucleation of ferrite plates at $450{ }^{\circ} \mathrm{C}$, as shown in Figure 6a. TiN and VN particles are considered as effective nucleation substrates, primarily due to a low lattice mismatch ratio with ferrite ( $3 \%$ and $1.3 \%$, respectively), particularly as a layer at MnS inclusions [25-29]. Bearing in mind the chemical composition of the steel, other complex particles such as CuS/MnS could 
also be considered as a potential nucleation site for the acicular ferrite [30,31]. The EDS spectrum of the particle in Figure $6 \mathrm{~b}$, shows an example of ferrite plate nucleation at the complex MnS particle with V. Although the intensity peak for V is weak, the presence of VN particles cannot be ruled out since MnS inclusions themselves are considered inactive for the intragranular nucleation of ferrite [29]. In addition to the effect of particles, segregations of $\mathrm{V}$ solutes may also act in favor of intragranular nucleation by rendering austenite grain boundaries inactive for bainite nucleation [32,33]. Furthermore, relatively large prior austenite grain size, as estimated to be $60 \mu \mathrm{m}$, also contributes to the intragranular nucleation, which is in agreement with results of previous investigations for critical grain size for acicular ferrite formation [17,31,34-36]. It could be concluded that the nucleation shift from the grain boundary to the grain interiors was determined not only by the presence of suitable second phase particles but also by the chemical composition of the austenite, characterized by the relatively high content of carbon and containing substitutional alloying elements, among which $\mathrm{V}$ is considered to be particularly influential. In addition to rendering grain boundaries less active for nucleation of bainite, it could be assumed that $\mathrm{V}$ in solid solution would promote the formation of ferrite by lowering the energy for nucleation of bcc phases [32].
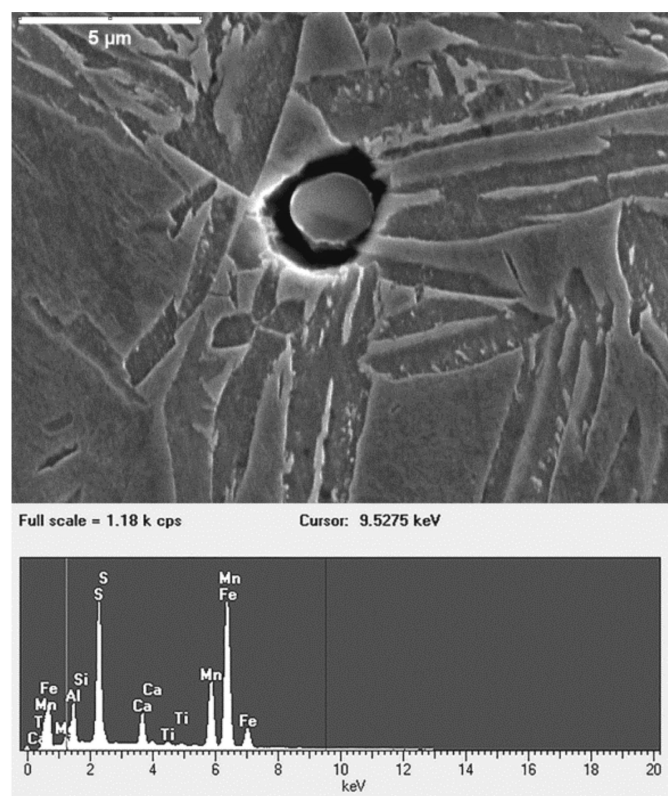

(a)
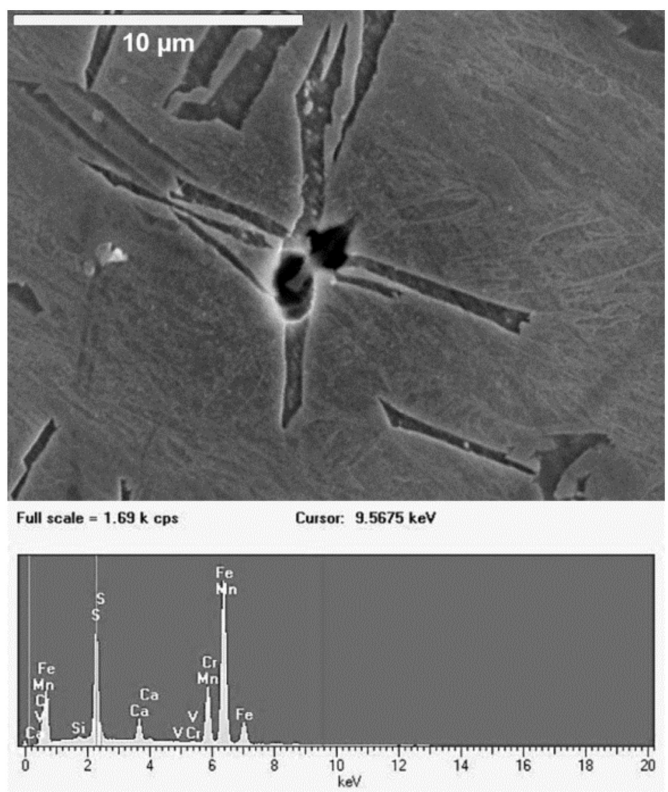

(b)

Figure 6. SEM images and EDS spectrums of the particles at which ferrite plates nucleate at: (a) $450{ }^{\circ} \mathrm{C} / 20 \mathrm{~s},(\mathbf{b})$ at $500{ }^{\circ} \mathrm{C} / 30 \mathrm{~s}$.

At $550{ }^{\circ} \mathrm{C}$ and $600{ }^{\circ} \mathrm{C}$, austenite transforms entirely by diffusional mechanism into a mixture of grain boundary ferrite allotriomorphs, intragranular ferrite idiomorphs, and pearlite (Figure 2e,f). Individual Widmanstätten side plates growing from the grain boundaries could also be observed, particularly in the microstructure of the specimen held at $550{ }^{\circ} \mathrm{C}$, probably due to an effect of higher undercooling [24,37]. Firstly, the number of ferrite nuclei increases with undercooling, and at the same time, the mobility ratio of the incoherent-to-coherent $\alpha / \gamma$ interphase boundaries increases, and therefore more elongated morphologies such as Widmanstätten ferrite side plates appear [38]. The light gray area in the micrographs is the martensite (M). After transformation times longer than $600 \mathrm{~s}$ at 550 and $600{ }^{\circ} \mathrm{C}$, no further change in microstructure occurs, i.e., microstructure consists of ferrite, pearlite, and austenite. Subsequent water cooling from the transformation temperatures will trigger austenite-martensite transformation, resulting in the final microstructure consisting of ferrite, pearlite, and martensite (Figure 2e,f). X-ray testing showed no significant content of retained austenite (less than $1 \%$ ). Therefore, austenite that remained untransformed, enriched in carbon and with a relatively high content of substitutional 
alloying elements, primarily $\mathrm{Cr}, \mathrm{Ni}$, and $\mathrm{V}$, had been in such condition at $550-600{ }^{\circ} \mathrm{C}$ that its further transformation became sluggish. In this case the influence of $\mathrm{V}$ could be assumed, having in mind its pronounced retarding effect on the diffusional transformation of the austenite [32] and the higher solubility of $\mathrm{V}(\mathrm{C}, \mathrm{N})$ particles in austenite [2].

\subsection{Compression Yield Strength}

Compressive stress-strain curves for the samples isothermally heat-treated at different temperatures are compared in the diagram in Figure 7. Corresponding values of compressive YS depending on the temperature of isothermal heat treatment are given in Figure 8.

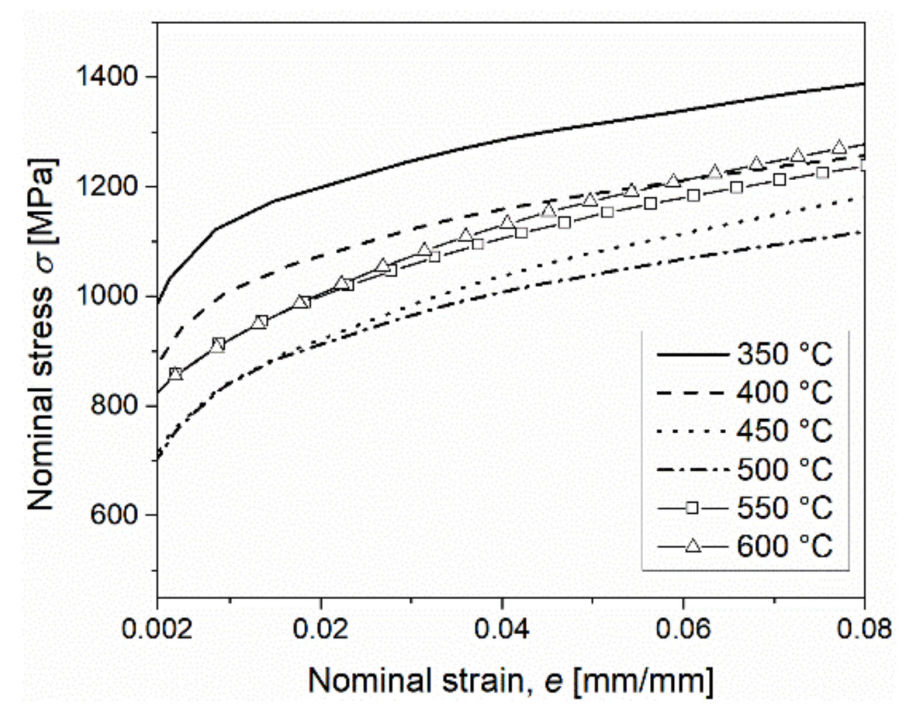

Figure 7. Compressive stress-strain curves for the Ti-V steel samples isothermally heat treated at different temperatures in the range from $350{ }^{\circ} \mathrm{C}$ to $600{ }^{\circ} \mathrm{C}$ for $1200 \mathrm{~s}$ and subsequently quenched in oil.

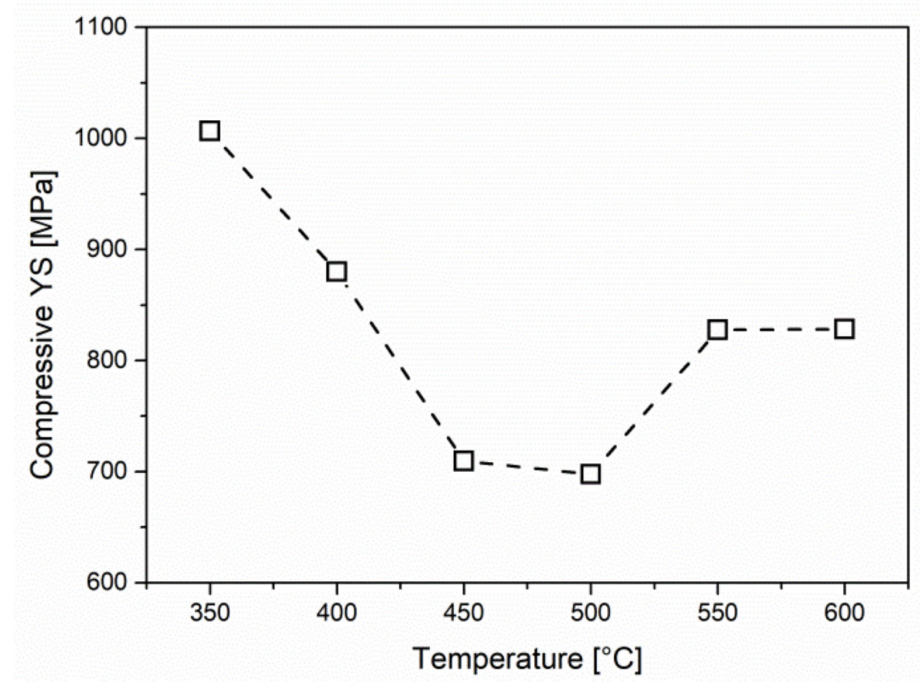

Figure 8. Compressive yield strength dependence on temperature of the isothermal heat treatment of the Ti-V steel examined (for $1200 \mathrm{~s}$ ).

The deformation of polycrystalline materials, both elastic and plastic, is generally the same in tension and compression. Therefore, Young's modulus, yield strength, and strainhardening curves obtained in tension and compression tests will be the same. Since both ultimate tensile strength and ductility depend on localized mechanisms of deformation and fracture, they are assumed to be principally different in tension and compression testing [39].

All six stress-strain curves show continuous hardening over the whole range of strain, i.e., no sharp yield points were observed, which is in good agreement with pre- 
vious results [11]. The shape of the deformation curves in Figure 7 suggests a higher work-hardening rate at the beginning of the deformation for the samples heat-treated at $350-500{ }^{\circ} \mathrm{C}$, compared with the samples held at $550-600{ }^{\circ} \mathrm{C}$. This is due to a higher dislocation density in the bainite and acicular ferrite, as a consequence of the displacive nature of transformation [11].

Compressive YS change with the temperature of isothermal heat treatment (Figure 8) can be rationalized in terms of grain size, dislocation density, precipitation hardening, and solid solution strengthening contributions.

Between $350{ }^{\circ} \mathrm{C}$ and $450{ }^{\circ} \mathrm{C}$ compressive yield strength decreases markedly, from about $1000 \mathrm{MPa}$ down by approximately $300 \mathrm{MPa}$, with the change of the microstructure from the sheaf type lower bainite to the coarser acicular ferrite structure. Lower bainite is known to be characterized by the high dislocation density and fine dispersion of carbides precipitated from the supersaturated bainitic ferrite $[38,40]$. However, such a high value of compressive YS also implies the possible presence of martensite in the structure. Carbon diffused from the growing bainite plates enriches surrounding austenite, making it more stable until the reaction completely stops. This effect is characteristic of the bainite reaction and is known as an incomplete reaction phenomenon [23]. Consequently, areas of untransformed austenite between bainitic plates transform to martensite upon quenching [21,31]. The marked decrease of compressive YS at $400{ }^{\circ} \mathrm{C}$ and further decrease at $450{ }^{\circ} \mathrm{C}$ is associated with the formation of acicular ferrite along with the increasing contribution of coarser ferrite morphologies, such as Widmanstätten ferrite (a group of coarse irregular grains in Figure 2c). The effect of lower undercooling and the shift of nucleation events from the austenite grain boundaries to the grain interiors results in the overall coarser ferrite structure. It is also accompanied by the decrease of dislocation density with the temperature of isothermal transformation, due to diminishing contribution of the displacive transformation mechanism and the coarser cementite dispersion, characteristic of upper acicular ferrite, as designated by some authors as analogous with upper bainite [31]. Furthermore, it should be mentioned that as austenite is more saturated on carbon at higher temperatures, it may be rendered more stable in regard to martensitic transformation on quenching the sample from the temperature of isothermal heat treatment [31]. In this respect, retained austenite would also contribute to the observed decrease in yield strength. However, in the context of the observed high strength values of the samples treated at $350{ }^{\circ} \mathrm{C}$, it could be first and foremost expected that the effect of incomplete reaction phenomenon diminishes with the temperature of isothermal transformation [23].

The low yield strength of the specimen subjected to isothermal decomposition at $500{ }^{\circ} \mathrm{C}$ could be associated with a higher amount of coarse ferrite with low dislocation density. Despite the coarser microstructure along the assumed lower dislocation density, compressive YS remains at the same level as it did at $450{ }^{\circ} \mathrm{C}$, probably due to the presence of fine pearlite.

An increase of compressive YS for the samples held at $550{ }^{\circ} \mathrm{C}$ and $600{ }^{\circ} \mathrm{C}$ could be related to the increased content of fine pearlite in the microstructure [41]. Additionally, a certain contribution of precipitation hardening by submicron $V(C, N)$ particles could also be expected. It is well established that $\mathrm{V}(\mathrm{C}, \mathrm{N})$ particles precipitated by interphase precipitation in ferrite, as arrays of fine particles at the moving $\gamma / \alpha$ interface during transformation, have a pronounced effect on the strength of the steels [42-45]. According to some authors, precipitation hardening might contribute up to $300 \mathrm{MPa}$ to the yield strength of the steel $[46,47]$. However, the martensite formed upon quenching from the untransformed austenite (the light gray area at the micrographs in Figure 2e,f) contributes to the detected increase of the strength. Therefore, it could be concluded that the finish of the transformation was delayed to a longer time, which could be explained by the increased hardenability of the steel as a result of the relatively high content of carbon and the additional influence of substitutional alloying elements. The enrichment of the austenite in carbon during transformation inhibits further progress of diffusional decomposition of austenite to pearlite $[11,19,48]$. Among other substitutional elements, such as $\mathrm{Cr}$ or 
$\mathrm{Ni}$, it is known that $\mathrm{V}$ in austenite solid solution markedly increases the hardenability of steels [2,33]. Having in mind the relatively high content of $\mathrm{V}$ in the steel and its higher solubility in austenite than in ferrite [2], a quantity of $\mathrm{V}$ in solid solution could be expected, which could explain the observed retardation of austenite decomposition and the delayed finish of transformation at $550{ }^{\circ} \mathrm{C}$ and $600{ }^{\circ} \mathrm{C}$.

\section{Conclusions}

1. Nucleation of bainite at grain boundaries of austenite at $350{ }^{\circ} \mathrm{C}$ shifts to the grain interiors, at complex particles with $\mathrm{MnS}$ core, and acicular ferrite becomes predominant at $400{ }^{\circ} \mathrm{C}$ and $450{ }^{\circ} \mathrm{C}$, which is ascribed to the increased contribution of sympathetic nucleation, the presence of suitable second phase particles for intragranular nucleation, and the influence of $\mathrm{V}$ in solid solution.

2. The high compressive $\mathrm{YS}$ of the samples isothermally treated at $350{ }^{\circ} \mathrm{C}$ is attributed to the incomplete reaction phenomenon and the consequent formation of the martensite upon the water quenching.

3. Formation of acicular ferrite at $400{ }^{\circ} \mathrm{C}$ and $450{ }^{\circ} \mathrm{C}$ is accompanied by a noticeable decrease of compressive YS.

4. Lowest compressive $\mathrm{YS}$ attained at $500{ }^{\circ} \mathrm{C}$ is related to the formation of coarse ferrite grains, formed by the nucleation of Widmanstätten ferrite plates and the process of their coalescence and further growth by diffusional mechanism at $500{ }^{\circ} \mathrm{C}$.

5. Transformation of the austenite to ferrite and pearlite at $550-600{ }^{\circ} \mathrm{C}$ is characterized by the delay of transformation finish, due to the influence of relatively high content of $\mathrm{C}$ and substitutional alloying elements, $\mathrm{Cr}$ and $\mathrm{Ni}$, but in particular $\mathrm{V}$ on retardation of diffusion in austenite.

Author Contributions: Conceptualization, D.G. and N.R.; methodology, N.R. and D.G.; validation, N.R.; formal analysis, S.D. and A.F.; investigation, S.D. and A.F.; resources, S.D., D.G. and N.R.; data curation, S.D.; writing—original draft preparation, S.D.; writing—review and editing, D.G., G.J. and N.R.; visualization, S.D. and G.J; supervision, N.R. All authors have read and agreed to the published version of the manuscript.

Funding: This work was supported by the Ministry of Education, Science and Technological Development of the Republic of Serbia (Contract No. 451-03-68/2020-14/200135). The authors acknowledge the support from the Serbian Ministry of Science under project ON 174004. This work was carried out in partial fulfillment of the requirements for the Ph.D. degree of Dikić Stefan at the University of Belgrade-Faculty of Technology and Metallurgy.

Institutional Review Board Statement: Not Applicable.

Informed Consent Statement: Not Applicable.

Data Availability Statement: Data sharing is not applicable to this article because all relevant data are presented in the tables and images of this article.

Conflicts of Interest: The authors declare no conflict of interest. The funders had no role in the design of the study; in the collection, analyses, or interpretation of data; in the writing of the manuscript; or in the decision to publish the results.

\section{References}

1. Krauss, G.; Banerji, S.K. Fundamentals of Microalloying Forging Steel. Metall. Soc. TMS 1987, 55. [CrossRef]

2. Langeborg, R.; Hutchinson, B.; Siwecki, T.; Zajac, S. The Role of Vanadium in Microalloyed Steels. Scand. J. Metall. 1999, 28, 186-241.

3. Fernández, J.; Illescas, S.; Guilemany, J.M. Effect of microalloying elements on the austenitic grain growth in a low carbon HSLA steel. Mater. Lett. 2007, 61, 2389-2392. [CrossRef]

4. Garcia-Mateo, C.; Capdevila, C.; Caballero, F.G.; Andrés, C.G. De Influence of V Precipitates on Acicular Ferrite Transformation Part 1: The Role of Nitrogen. ISIJ Int. 2008, 48, 1270-1275. [CrossRef]

5. Gomez, M.; Rancel, L.; Escudero, E.; Medina, S.F. Phase Transformation under Continuous Cooling Conditions in Medium Carbon Microalloyed Steels. J. Mater. Sci. Technol. 2014, 30, 511-516. [CrossRef] 
6. Garcia de Andres, C.; Capdevila, C.; Caballero, F.G.; San Martin, D. Effect of molybdenum on continuous cooling transformations in two medium carbon forging steels. J. Mater. Sci. 2001, 36, 565-571. [CrossRef]

7. Khodabandeh, A.R.; Jahazi, M.; Yue, S.; Bocher, P. Impact Toughness and Tensile Properties Improvement through Microstructure Control in Hot Forged Nb-V Microalloyed Steel. ISIJ Int. 2005, 45, 272-280. [CrossRef]

8. Babu, S.S.; Bhadeshia, H.K.D.H. Mechanism of the Transition from Bainite to Acicular Ferrite. JIM 1991, 32, 679-688. [CrossRef]

9. Glišić, D.; Radović, N.; Koprivica, A.; Fadel, A.; Drobnjak, D. Influence of Reheating Temperature and Vanadium Content on Transformation Behavior and Mechanical Properties of Medium Carbon Forging Steels. ISIJ Int. 2010, 50, 601-606. [CrossRef]

10. Madariaga, I.; Gutierrez, I.; Bhadeshia, H.K.D.H. Acicular Ferrite Morphologies in a Medium-Carbon Microalloyed Steel. Metall. Mater. Trans. A 2001, 32, 2187-2197. [CrossRef]

11. Bhadeshia, H.K.D.H. Bainite in Steels; IOM Communications Ltd.: London, UK, 2001; ISBN 1861251122.

12. Ishikawa, F.; Takahashi, T.; Ochi, T. Intragranular Ferrite Nucleation in Medium-Carbon Vanadium Steels. Metall. Mater. Trans. A 1994, 25, 929-936. [CrossRef]

13. Fadel, A. Austenite Decomposition in Medium Carbon Microalloyed Steels: Meshanism, Structure and Properties. Ph.D. Thesis, University of Belgrade, Belgrade, Serbia, 2013.

14. Hu, J.; Du, L.X.; Xie, H.; Gao, X.H.; Misra, R.D.K. Microstructure and mechanical properties of TMCP heavy plate microalloyed steel. Mater. Sci. Eng. A 2014, 607, 122-131. [CrossRef]

15. Garcia-Mateo, C.; Cornide, J.; Capdevila, C.; Caballero, F.G.; Garcia de Andres, C. Influence of V Precipitates on Acicular Ferrite Transformation Part 2: Transformation Kinetics. ISIJ Int. 2008, 48, 1276-1279. [CrossRef]

16. Siwecki, T.; Eliasson, J.; Langeborg, R.; Bevis, H. Vanadium Microalloyed Bainitic Hot Strip Steels. ISIJ Int. 2010, 50, 760-767. [CrossRef]

17. Garcia de Andres, C.; Caballero, F.G.; Capdevila, C.; San Martin, D. Revealing austenite grain boundaries by thermal etching: Advantages and disadvantages. Mater. Charact. 2003, 49, 121-127. [CrossRef]

18. Kirkaldy, J.S. Prediction of Microstructure and Hardenability in Low Alloy Steels. In: Phase Transformations in Ferrous Alloys. In Prediction of Microstructure and Hardenability in Low Alloy Steels, Proceedings of the Phase Transformations in Ferrous Alloys, Philadelphia, PA, USA, 4-6 October 1983; AIME: Warrendale, PA, USA, 1983; pp. 125-148.

19. Diaz-Fuentes, M.; Gutiérrez, I. Analysis of different acicular ferrite microstructures generated in a medium-carbon molybdenum steel. Mater. Sci. Eng. A 2003, 363, 316-324. [CrossRef]

20. Aaronson, H.I.; Spanos, G.; Masamura, R.A.; Vardiman, R.G.; Moon, D.W.; Menon, E.S.K.; Hall, M.G. Sympathetic nucleation: An overview. Mater. Sci. Eng. B 1995, 32, 107-123. [CrossRef]

21. Aaronson, H.I.; Reynolds, W.T.; Purdy, G.R. The Incomplete Transformation Phenomenon in Steel. Metall. Mater. Trans. A 2006, 37, 1731-1745. [CrossRef]

22. Wu, K.M.; Enomoto, M. Three-dimensional morphology of degenerate ferrite in an Fe-C-Mo alloy. Scr. Mater. 2002, 46, 569-574. [CrossRef]

23. Bhadeshia, H.K.D.H. Bainite in Steels Theory and Practice, 3rd ed.; Maney Publishing: London, UK, $2015 ;$ ISBN 9781909662742.

24. Okaguchi, S.; Ohtani, H.; Ohmori, Y. Morphology of Widmanstatten Bainitic Ferrites. Mater. Trans. 1991, 32, 697-704. [CrossRef]

25. Ishikawa, F.; Takahashi, T. The Formation ot Intragranular Ferrite Steels for Hot-torging and Its Effect on Plates in Medium-carbon the Toughness. ISIJ Int. 1995, 35, 1128-1133. [CrossRef]

26. Shim, J.; Oh, Y.; Suh, J.; Cho, Y.W.; Shim, J.; Byun, J. Ferrite Nucleation Potency of Non-Metallic Inclusions in Medium Carbon Steels. Acta Mater. 2001, 49, 2115-2122. [CrossRef]

27. Jin, H.H.; Shim, J.H.; Cho, Y.W.; Lee, H.C. Formation of Intragranular Acicular Ferrite Grains in a Ti-containing Low Carbon Steel. ISIJ Int. 2003, 43, 1111-1113. [CrossRef]

28. Zhang, S.; Hattori, N.; Enomot, M.; Taru, T. Ferrite Nucleation at Ceramic/Austenite Interface. ISIJ Int. 1996, 36, 1301-1309. [CrossRef]

29. Sarma, D.S.; Karasev, A.V.; Jönsson, P.G. On the Role of Non-metallic Inclusions in the Nucleation of Acicular Ferrite in Steels. ISIJ Int. 2009, 49, 1063-1074. [CrossRef]

30. Madariaga, I.; Gutierrez, I. Role of the Particle-Matrix Interface on the Nucleation of Acicular Ferrite in a Medium Carbon Microalloyed Steel. Acta Mater. 1999, 47, 951-960. [CrossRef]

31. Madariaga, I.; Romero, J.L.; Gutie, I. Upper Acicular Ferrite Formation in a Medium-Carbon Microalloyed Steel by Isothermal Transformation: Nucleation Enhancement by CuS. Metall. Mater. Trans. A 1998, 29, 1003-1015. [CrossRef]

32. He, K.; Edmonds, D.V. Formation of Acicular Ferrite and Influence of Vanadium Alloying. Mater. Sci. Technol. 2002, 18, 289-296. [CrossRef]

33. Adrian, H. A mechanism for effect of vanadium on hardenability of medium carbon manganese steel. Mater. Sci. Technol. 1999, 15, 366-378. [CrossRef]

34. Garcia de Andres, C.; Capdevila, C.; Caballero, F.G.; San Martin, D. Effect of the microalloying elements on nucleation of allotriomorphic ferrite in medium carbon-manganese steels. J. Mater. Sci. 2001, 20, 1135-1137. [CrossRef]

35. Capdevila, C.; Ferrer, J.P.; Garcia-Mateo, C.; Caballero, F.G.; Lopez, V.; Garcia de Andres, C. Influence of Deformation and Molybdenum Content on Acicular Ferrite Formation in Medium Carbon Steels Ferrite Formation in Medium Carbon Steels. ISIJ 2006, 46, 1093-1100. [CrossRef]

36. Garcia de Andres, C.; Bartolome, M.J.; Capdevila, C.; San Martın, D.; Caballero, F.G.; Lopez, F.G. Metallographic techniques for the determination of the austenite grain size in medium-carbon microalloyed steels. Mater. Charact. 2001, 46, 389-398. [CrossRef] 
37. Bhadeshia, H.K.D.H. Physical Metallurgy of Steels, 4th ed.; Elsevier: Amsterdam, Netherlands, 2014; Volume 1, ISBN 9780444537713.

38. Bhadeshia, H.K.D.H.; Honeycombe, R.W.K. Steels Microstructure and Properties; Elsevier Ltd.: Amsterdam, The Netherlands, 2006; ISBN 9780750680844.

39. Kuhn, H.; Medlin, D. Mechanical Testing and Evaluation; ASM International: Material Park, OH, USA, 2000. [CrossRef]

40. Bhadeshia, H.K.D.H.; Christian, J.W. Bainite in Steels. Metall. Trans. A 1990, 21, 767-797. [CrossRef]

41. Pereloma, E.; Edmonds, D. V Phase Transformations in Steels, 1st ed.; Elsevier: Amsterdam, The Netherlands, 2012; Volume 1, ISBN 978-1-84569-970-3.

42. Miyamoto, G.; Hori, R.; Poorganji, B.; Furuhara, T. Interphase Precipitation of VC and Resultant Hardening in V-added Medium Carbon Steels. ISIJ Int. 2011, 51, 1733-1739. [CrossRef]

43. Zhang, J.; Wang, F.; Yang, Z.; Li, C. Microstructure, Precipitation, and Mechanical Properties of V-N-Alloyed Steel After Different Cooling Processes. Metall. Mater. Trans. A 2016, 47, 6621-6631. [CrossRef]

44. Kestenbach, H.; Gallego, J. On Dispersion Hardening of Microalloyed Hot Strip Steels by Carbonitride Precipitation in Austenite. Scr. Mater. 2001, 44, 791-796. [CrossRef]

45. Kestenbach, H.; Campos, S.S.; Morales, E.V. Role of interphase precipitation in microalloyed hot strip steels. Mater. Sci. Technol. 2006, 22, 615-626. [CrossRef]

46. Chen, J.; Lv, M.; Tang, S.; Liu, Z.; Wang, G. Influence of cooling paths on microstructural characteristics and precipitation behaviors in a low carbon V-Ti microalloyed steel. Mater. Sci. Eng. A 2014, 594, 389-393. [CrossRef]

47. Funakawa, Y.; Shiozaki, T.; Tomita, K.; Yamamoto, T.; Maeda, E. Development of High Strength Hot-rolled Sheet Steel Consisting of Ferrite and Nanometer-sized Carbides. ISIJ Int. 2004, 44, 1945-1951. [CrossRef]

48. Bhadeshia, H.K.D.H.; Edmonds, D.V. The Bainite Transformation in a Silicon Steel. Metall. Mater. Trans. A Phys. Metall. Mater. Sci. 1979, 10, 895-907. [CrossRef] 